\title{
A Hierarchical Spatial Framework and Database for the National River Fish Habitat Condition Assessment
}

\section{Lizhu Wang}

Institute for Fisheries Research, Michigan Department of Natural Resources and University of Michigan, 212 Museums Annex, Ann Arbor, MI 48109. E-mail: wang1@michigan.gov

\section{Dana Infante}

Department of Fisheries and Wildlife, Michigan State University, East Lansing, MI 48824

\section{Peter Esselman}

Institute for Fisheries Research, Michigan Department of Natural Resources and University of Michigan, 212 Museums Annex, Ann Arbor, MI 48109; and Department of Fisheries and Wildlife, Michigan State University, East Lansing, MI 48824

\section{Arthur Cooper}

Institute for Fisheries Research, Michigan Department of Natural Resources and University of Michigan, 212 Museums Annex, Ann Arbor, MI 48109; and Department of Fisheries and Wildlife, Michigan State University, East Lansing, MI 48824

\section{Dayong Wu}

Department of Life Science, Hengshui University, Hengshui, Hebei, China 053000

\section{William Taylor}

Department of Fisheries and Wildlife, Michigan State University, East Lansing, MI 48824

\section{Doug Beard}

National Climate Change and Wildlife Science Center, U.S. Geological Survey, 12201 Sunrise Valley Drive, Reston, VA 20192

\section{Gary Whelan}

Fisheries Division, Michigan Department of Natural Resources, 530 West Allegan, Lansing, MI 48909

\section{Andrea Ostroff}

National Climate Change and Wildlife Science Center, U.S. Geological Survey, 12201 Sunrise Valley Drive, Reston, VA 20192

ABSTRACT: Fisheries management programs, such as the National Fish Habitat Action Plan (NFHAP), urgently need a nationwide spatial framework and database for health assessment and policy development to protect and improve riverine systems. To meet this need, we developed a spatial framework and database using $\mathrm{Na}$ tional Hydrography Dataset Plus (1:100,000-scale); http://www. horizon-systems.com/nhdplus). This framework uses interconfluence river reaches and their local and network catchments as fundamental spatial river units and a series of ecological and political spatial descriptors as hierarchy structures to allow users to extract or

\section{Base de Datos y Marco Jerárquico- Espacial para la Evaluación Nacional de Hábitat de Peces Fluviales}

RESUMEN: Los programas de manejo de pesquerías, tal como el Plan de Evaluación Nacional de Hábitat de Peces Fluviales (ENHPF) demandan urgentemente de un marco conceptual y de una base de datos para la realización de evaluaciones del estado de salud y establecimiento de políticas de desarrollo para proteger y mejorar los sistemas fluviales. Con el fin de satisfacer esta necesidad, en la presente contribución se desarrolla un marco jerárquico-espacial y una base de datos utilizando la Base Nacional de Datos Hidrográficos 1:100,000. El marco conceptual toma la inter-confluencia de los ríos y la red de cuencas como unidades espaciales fundamentales. Además de una serie de descriptores ecológicos y políticos como estructuras jerárquicas que permiten al usuario extraer o analizar información en las escalas espaciales de su preferencia. Esta base de daros consiste en variables que describen las características del canal, posición y conectividad de la red, clima, elevación, gradiente y tamaño. Contiene una serie de factores naturales y antropogénicos relativos a la captación cuya influencia sobre las caracteristicas de los ríos es bien conocida. El marco conceptual y la base de datos ensamblan por primera vez todos los ríos de los Estados Unidos de Norteamérica, y sus descriptores. El marco y la base de datos ofrecen al usuario la posibilidad de agregar información, realizar análisis, desarrollar escenarios de manejo y regulación y dar seguimiento a los procesos del manejo en distintas escalas espaciales. Esta base de datos provee la información esencial para cumplimentar los objetivos del ENHPF así como de otros programas de manejo,. La versión beta descargable de la base de datos está disponible en http://ec2-184-73-40-15.compute-1.amazonaws.com/ nfhap/main/.

analyze information at spatial scales that they define. This database consists of variables describing channel characteristics, network position/connectivity, climate, elevation, gradient, and size. It contains a series of catchment-natural and human-induced factors that are known to influence river characteristics. Our framework and database assembles all river reaches and their descriptors in one place for the first time for the conterminous United States. This framework and database provides users with the capability of adding data, conducting analyses, developing management scenarios and regulation, and tracking management progresses at a variety of spatial 
scales. This database provides the essential data needs for achieving the objectives of NFHAP and other management programs. The downloadable beta version database is available at http://ec2-18473-40-15.compute-1.amazonaws.com/nfhap/main/.

\section{Introduction}

The National Fish Habitat Action Plan (NFHAP) is a partnership-driven, nonregulatory, and science-based effort to enhance and conserve fish habitats throughout inland and coastal waters of the United States. Its primary goals are to protect healthy aquatic systems, prevent further degradation, and reverse declines in the quality and quantity of aquatic habitats. One of the short-term objectives of the NFHAP is to conduct a condition analysis of all fish habitat within the United States and identify national priority habitats for resource allocation and management prioritization from this analysis (http://www. fishhabitat.org).

To achieve these goals and objectives, the NFHAP urgently needs a spatial framework and database that provides nationwide information on the amount of fish habitats by type, condition, and location. Such a spatial framework and database must (1) have an integrated, objective standard for nationwide habitat condition comparison; (2) allow decision makers to use available data and assessment results to quickly identify areas of highest priority and the most cost-effective locations for protection, enhancement, and rehabilitation; and (3) have a reporting framework that allows the activities and progress of regional partnerships who are addressing priority habitats to be synthesized and reported at regional and national scales. Prior to this effort, a nationwide database and spatial framework meeting such needs was not available.

During the past several decades, the assessment of national water conditions has been carried out mainly by state water quality agencies, and the results have been reported biannually to the U.S. Environmental Protection Agency (EPA) under the requirement of Section 305(b) of the Clean Water Act. This national report and associated database does not meet the needs of the NFHAP because the inventory methods and assessment criteria are inconsistent among states, and the representation of the nation's water by subsamples of sites representing only a small percentage of national waters is uncertain (General Accounting Office 2000). The EPA's Environmental Monitoring and Assessment Program and the Wadeable Stream Assessment (WSA) Program used standardized probability sampling design. Those programs provide a statistically defensible generalization of conditions of the nation's waters and have markedly improved the representation of regional data summaries (Stoddard et al. 2005; EPA 2006). However, such data are inappropriate for providing information to unsampled parts of rivers in different landscape settings.
The failure of the existing national assessment databases in meeting the NFHAP needs relates to the fact that those assessments have predominantly focused on instream sampling. Such approaches require intensive field sampling of stressors and indicators and do not provide sufficient information for all aquatic habitats nationwide. An alternative approach relies on the increased availability of regional and national databases developed with geographic information systems (GIS) to directly assess sources of habitat degradation. Recent explorations of such an approach have been shown to be feasible and of proven effectiveness at regional scales (Mattson and Angermeier 2007; Wang et al. 2008, 2010). This approach is feasible because landscape alterations associated with human disturbances are the major cause of degradation to aquatic habitats and biological assemblages (Gergel et al. 2002; Allan 2004; Wang et al. 2006), and source-stressor-indicator relationships are well established (Karr and Chu 1997; Wang et al. 2008). This approach is also effective because it uses readily available data sets and GIS techniques, which make it possible to assess all aquatic habitats nationwide within a relatively short time period.

Under the guidance of the NFHAP Board's Science and Data Committee- and with support from the U.S. Fish and Wildlife Service and the U.S. Geological Survey (USGS) —an effort was initiated in 2007 to assess the nation's fish habitat conditions of inland waters. This effort has resulted in the development of an operational database and reporting framework that have basic spatial mapping units for all streams and rivers in the conterminous 48 states. This database has a hierarchical spatial structure that allows attribution of regional data with different spatial resolutions; allows data to be synthesized and reported at various spatial scales; and is flexible for attributing additional local data and for reporting at any needed spatial scale. This effort has attributed the database with appropriate national data that describe natural variation in river conditions and human disturbances and available biological data that may indicate river health conditions. This effort has made an initial assessment of riverine habitat condition, including the amount, types, health status and causes of degradation of different river habitats in the conterminous 48 states (Esselman et al. 2011).

The objectives of this article are to (1) describe the database hierarchical spatial structure, data sources, and the GIS processes used to attribute data into the database; (2) report briefly on a riverine aquatic habitat resource and its patterns in natural variation and levels of human disturbances at different spatial scales; and (3) illustrate the utility of the database and framework. See Esselman et al. (2011) for the national fish habitat condition assessment, which will not be reported here. 


\section{Database Heirarchical Spatial Struc- ture, Data Sources, and GIS Processes}

\section{Basic Spatial River Mapping Units and Their Network Connectivity and Catchments}

To develop the hierarchy spatial framework for assessing the condition of the nation's riverine fish habitats using human disturbance sources in the place of instream stressors or indicators, we first defined the finest spatial river unit boundaries that are ecologically meaningful and mappable nationwide using GIS tools. We then defined each river unit's position and connectivity within its river network and its land and water area boundaries within which human activities affect the unit. This is because the conditions of the spatial unit of a river network are not only influenced by the physicochemical and biological condition within the unit but also by its connectivity with the network, conditions in its riparian and floodplain zones, and natural and human factors in its local and network catchments (Wang et al. 2003, 2008; Higgins et al. 2005).

We used the river networks and associated catchments of National Hydrography Database Plus (NHDPlus) as the backbone for building the spatial framework and database. The NHDPlus is a $1: 100,000$-scale stream-line GIS database that includes all streams and rivers captured at this resolution, which is the best available nationwide data for rivers in the United States at the time of this study. Stream lines in the NHDPlus are divided into fundamental reaches (smallest spatial units; hereafter referred to as "river reaches") that are defined from the origin of a stream to a confluence at the downstream end, from a confluence to a confluence, from a confluence to the upstream end of an impoundment, from the downstream end of an impoundment to a confluence, or from a confluence to a pour point with the sea or lakes with no outlet (Brenden et al. 2006). These river reaches are the finest spatial units in our geographic framework. Within the database, the local catchment (the land area where surface runoff flows directly into the reach) and network catchment (the entire catchment area upstream of the downstream end of the reach) boundaries of each reach are delineated. This database covers the entire conterminous United States and has a topological structure (e.g., flow direction and neighbor river unit descriptor) that makes it feasible to calculate multiple river connectivity and network position variables using GIS tools.

\section{Selection and Attribution of GIS Data}

We only incorporated data that cover the entire conterminous United States at the highest resolution available. One type of variable attributed to each river reach captures the values of natural variations in climate, elevation, geology, soil, land cover, groundwater contribution, and river size and connectivity that can serve as surrogates of reach-level natural variation in physicochemical and biological characteristics (Table 1). Some of these descriptors of natural variation such as network catchment size, Strahler order, reach length, reach mean elevation, reach gradient, and mean annual air temperature and precipitation were from the NHDPlus database. The other natural variables, such as soil permeability, types of surficial geology, and groundwater contribution were calculated based on Internet data sources (Table 1) using GIS tools. The other type of variable measures variation in human activities in the river channels, riparian and floodplain, and catchments. River reach human disturbance descriptors, representing land uses, population density, transportation, nutrient enrichment, agricultural pollutants, dams, and point source pollutions, were gathered based on various data sources (Table 1) and their known influences on river health (Wang et al. 2003, 2008). We first attributed both natural and human activity variables in the local catchment to each river reach using ArcInfo's ZonalStats function for continuous and Arc Macro Language programs for categorical variables. We then attributed network catchment data to each river reach by summarizing each variable from all local catchments upstream of each reach using the NHDPlus Catchment Attribute Allocation and Accumulation Tool (http://www.horizon-systems.com/nhdplus/tools.php).

\section{Selection and Attribution of Ecological and Political Spatial Descriptors}

In addition to the variables measuring river reach natural variations and human disturbances, we attributed key ecological spatial hierarchical classes, biological assessment ecoregions, and political boundaries to each river reach. The ecological spatial classes included Freshwater Ecoregions of North America (FENA; Abell et al. 2000) and Ecological Drainage Units (EDUs; Higgins et al. 2005; Sowa et al. 2007); the biological assessment regions included the EPA's "aggregated ecoregions" (Pont et al. 2009) and the Hydrological Unit Code (HUC; Seaber et al. 1987); and the political boundaries included the locations of the National Fish Habitat Partnerships (FHPs) that have been recognized by the National Fish Habitat Action Plan Board and boundaries of states.

Freshwater ecoregions and EDUs are widely used geospatial units for biological conservation planning. A freshwater ecoregion is defined as a relatively large area of water with associated land that contains a geographically distinct assemblage of natural communities (Abell et al. 2000). The FENAs that we used were developed by Abell et al. (2000) based on the U.S. Department of Agriculture Forest Service's mapping project (Maxwell et al. 1995). EDUs represent regional biological community distinctions within a FENA unit (Higgins et al. 2005, Sowa et al. 2007). Though EDUs are ideally defined using knowledge of biological patterns from biogeography literature or multivariate analyses of species presence and absence, in practice EDUs are frequently delineated by identifying areas with similar abiotic patterns in physiography, climate, and connectivity because high-resolution species data are often lacking across large regions (Higgins et al. 2005). 
TABLE 1. Summary of natural and human disturbance data sources that were attributed to each of the river reaches and included in our database. NLCD = National Land Cover Database; NHDPlus = National Hydrography Dataset Plus; STATSGO = State Soil Geographic Database; TIGER = Topologically Integrated Geographic Encoding and Referencing System; SPARROW $=$ Spatially Referenced Regressions on Watershed Attributes; HUC $=$ Hydrologic Unit Code. Date = year or range of years for each data source.

\begin{tabular}{|c|c|c|c|}
\hline Description & Source & Resolution & Date \\
\hline \multicolumn{4}{|c|}{ Natural variables } \\
\hline Land cover-Deciduous forest & NLCD (http://www.mrlc.gov/) & $30 \mathrm{~m}$ & 2001 \\
\hline Land cover-Evergreen forest & NLCD (http://www.mrlc.gov/) & $30 \mathrm{~m}$ & 2001 \\
\hline Land cover-Mixed forest & NLCD (http://www.mrlc.gov/) & $30 \mathrm{~m}$ & 2001 \\
\hline Land cover-Open water & NLCD (http://www.mrlc.gov/) & $30 \mathrm{~m}$ & 2001 \\
\hline Land cover-Shrub/scrub & NLCD (http://www.mrlc.gov/) & $30 \mathrm{~m}$ & 2001 \\
\hline Land cover-Grassland/herbaceous & NLCD (http://www.mrlc.gov/) & $30 \mathrm{~m}$ & 2001 \\
\hline Land cover-Woody wetlands & NLCD (http://www.mrlc.gov/) & $30 \mathrm{~m}$ & 2001 \\
\hline Land cover-Open wetlands & NLCD (http://www.mrlc.gov/) & $30 \mathrm{~m}$ & 2001 \\
\hline Local catchment area & NHDPIus (http://www.horizon-systems.com/nhdplus) & $1: 100,000$ & 2007 \\
\hline Network catchment area & NHDPlus (http://www.horizon-systems.com/nhdplus) & $1: 100,000$ & 2007 \\
\hline Mean annual air temperature & NHDPlus (http://www.horizon-systems.com/nhdplus) & 4 km & 1961-1990 \\
\hline Mean annual precipitation & NHDPlus (http://www.horizon-systems.com/nhdplus) & $4 \mathbf{k m}$ & 1961-1990 \\
\hline Reach elevation & NHDPlus (http://www.horizon-systems.com/nhdplus) & $30 \mathrm{~m}$ & \\
\hline Reach slope & NHDPlus (http://www.horizon-systems.com/nhdplus) & $30 \mathrm{~m}$ & \\
\hline Reach stream order & NHDPlus (http://www.horizon-systems.com/nhdplus) & $1: 100,000$ & \\
\hline Reach linkage number & Calculated from NHDPlus & $1: 100,000$ & \\
\hline Soil permeability & USGS STATSGO (http://water.usgs.gov/GIS/metadata/usgswrd/XML/ussoils.xml) & $1: 250,000$ & 1995 \\
\hline Surficial lithography & Surficial geology (http://rmgsc.cr.usgs.gov/ecosystems/usa.shtml) & 1 km & 2009 \\
\hline \multicolumn{4}{|c|}{ Disturbance variables } \\
\hline Cattle density on farmland & USDA Agriculture Census (http://nationalatlas.gov/mld/agcensp.html) & County & 2002 \\
\hline Dam density & $\begin{array}{l}\text { USACE National Inventory of Dams (http://crunch.tec.army.mil/)nidpublic/webpages/ } \\
\text { nid.cfm }\end{array}$ & Point data & 2005 \\
\hline Estimated groundwater use & USGS Estimated Water Use in US (http://water.usgs.gov/watuse/) & County & 2000 \\
\hline Estimated surface water use & USGS Estimated Water Use in US (http://water.usgs.gov/watuse/) & County & 2000 \\
\hline Human population density & NOAA Population 2000 (http://www.ngdc.noaa.gov/dmsp/download_sprawl.html) & 1 km & 2000 \\
\hline Imperviousness & NLCD (http://www.horizon-systems.com/nhdplus) & $30 \mathrm{~m}$ & 2001 \\
\hline Land use-Pasture/hay & NLCD (http://www.horizon-systems.com/nhdplus) & $30 \mathrm{~m}$ & 2001 \\
\hline Land use-Cultivated crops & NLCD (http://www.horizon-systems.com/nhdplus) & $30 \mathrm{~m}$ & 2001 \\
\hline Land use-Open space urban & NLCD (http://www.horizon-systems.com/nhdplus) & $30 \mathrm{~m}$ & 2001 \\
\hline Land use-Low-intensity urban & NLCD (http://www.horizon-systems.com/nhdplus) & $30 \mathrm{~m}$ & 2001 \\
\hline Land use-Medium-intensity urban & NLCD (http://www.horizon-systems.com/nhdplus) & $30 \mathrm{~m}$ & 2001 \\
\hline Land use-High-intensity urban & NLCD (http://www.horizon-systems.com/nhdplus) & $30 \mathrm{~m}$ & 2001 \\
\hline Mining density & USGS Active Mines (http://tin.er.usgs.gov/mineplant/) & Point data & 2003 \\
\hline $\begin{array}{l}\text { National Pollutant Discharge } \\
\text { Elimination System Density }\end{array}$ & EPA Geodata Shapefile (http://www.epa.gov/enviro/geo_data.html) & Point data & 2007 \\
\hline Road crossing density & $\begin{array}{l}\text { Census } 2000 \text { TIGER Roads (http://www.esri.com/data/download/census2000-tiger- } \\
\text { line/index.html) }\end{array}$ & $1: 100,000$ & 2000 \\
\hline Road length density & $\begin{array}{l}\text { Census } 2000 \text { TIGER Roads (http://www.esri.com/data/download/census2000-tiger- } \\
\text { line/index.html) }\end{array}$ & $1: 100,000$ & 2000 \\
\hline $\begin{array}{l}\text { Superfund National Priority List } \\
\text { Density }\end{array}$ & EPA Geodata Shapefile (http://www.epa.gov/enviro/geo_data.html) & Point data & 2007 \\
\hline Toxics Release Inventory density & EPA Geodata Shapefile (http://www.epa.gov/enviro/geo_data.html) & Point data & 2007 \\
\hline Total phosphorus yield & USGS SPARROW (http://water.usgs.gov/nawqa/sparrow/wrr97/results.html) & 8-Digit HUC & 1974-1989 \\
\hline Total nitrogen yield & USGS SPARROW (http://water.usgs.gov/nawqa/sparrow/wrr97/results.html) & 8-Digit HUC & 1974-1989 \\
\hline
\end{tabular}


The aggregated ecoregions and HUCs are commonly used for biological assessment. The aggregated ecoregions were originally formed by merging Omernik's (1987) Level-III ecoregions, in order to assess and report the condition of river systems using macroinvertebrates (EPA 2006). Each aggregated ecoregion has similar landform and climate characteristics and has been used for developing large-scale bioassessment techniques and sampling designs (e.g., Pont et al. 2009). HUCs were created by dividing and subdividing the United States into successively smaller hydrologic units that are arranged in a nested fashion (Seaber et al. 1987). The 8-digit and 12-digit HUCs we used provide a standardized base for use by waterresources organizations in locating, storing, retrieving, and exchanging data.

The FHP and state are political boundaries within which assessment and management policies are often implemented. The geographic boundaries of FHPs are areas within which the partnerships work to conserve target aquatic features or species of interest. The geographic boundaries of FHPs are variable and may nest within natural drainage units, span multiple administrative states, and, in some cases, partially overlap with one another. Generally, one FHP contains multiple states, but not all parts of all states are included (http://fishhabitat.org/).

\section{Spatial Hierarchical Classification Framework}

River reach habitat characteristics and their associated biological communities are a result of integrated influences of climate, elevation, geology, soil, land cover, river network position and connectivity, and human activities in local and network catchments and interactions across ecological spatial hierarchical units (Frissell et al. 1986; Poff 1997; Wang et al. 2006). Arguably, fish habitat characteristics and their associated biological communities are also influenced by political boundaries and biological assessment regions, because management policies and their implementations often differ among these entities.

The smallest mappable spatial unit in our database is the river reach (Figure 1). Each river reach has unique local and network catchment boundaries and descriptors of river network

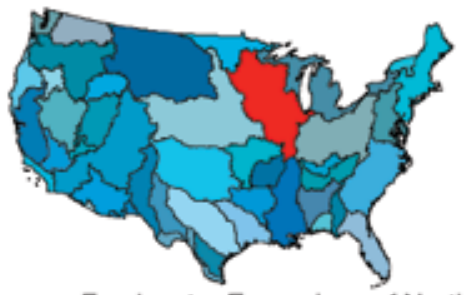

Freshwater Ecoregions of North America

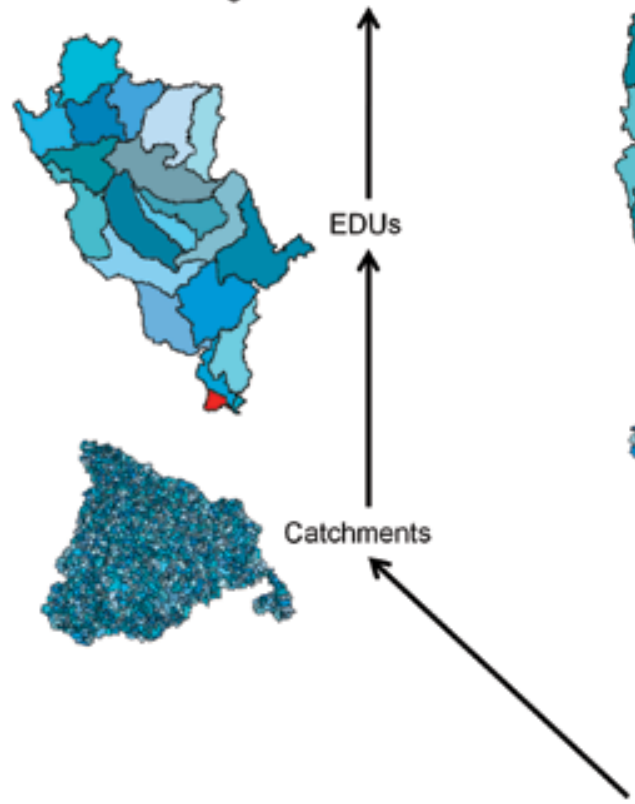

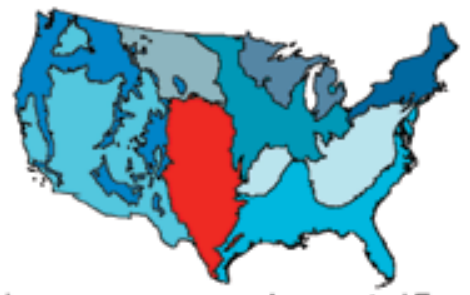

Aggregated Ecoregions
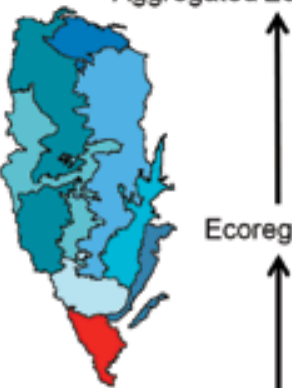

Ecore

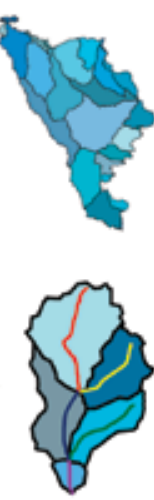

River reaches, local and network catchments coregions
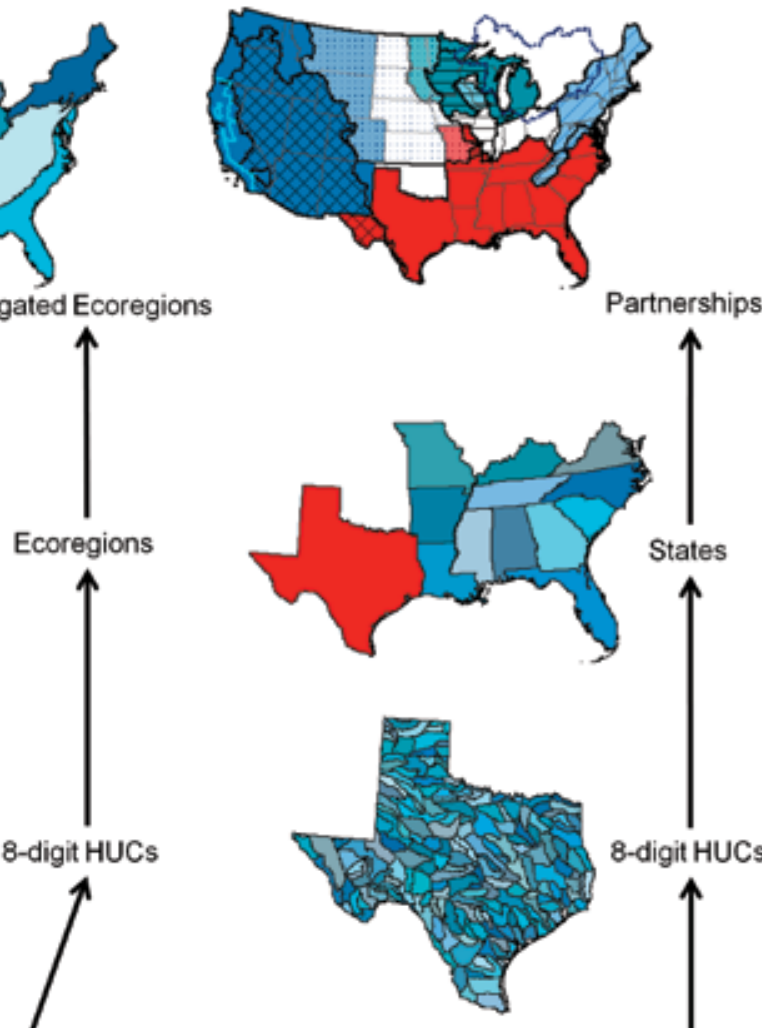

8-digit HUCs
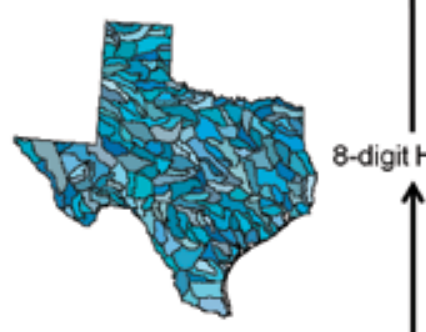

Figure 1. Database spatial framework. The smallest mappable spatial unit is a river reach and its associated local catchment. Data attributed to such river reach units can be aggregated into and analyzed at many larger hierarchal spatial scales 
position and connectivity. Each river reach is associated with a unique FENA, EDU, ecoregion, HUC, FHP, and state. The river reach, local catchment, network catchment, EDU, and FENA occur as a spatial hierarchical series. The local catchment associated with a river reach is nested within a network catchment; the network catchment is often, but not always, nested within an EDU; and the EDU is often nested within a FENA. Such a nested structure reflects the notion that factors defined at lower hierarchical spatial levels may be influenced by factors defined at higher levels (Frissell et al. 1986; Poff 1997; Wang et al. 2003, 2006). This nested structure has important implications for users. When answering basic ecological questions or identifying cause-effect factors at a river reach scale, researchers can evaluate or model not only what they see or can directly measure but can incorporate influences of abiotic and human activity factors at increasingly larger spatial scales upstream. When making management decisions, policy makers and managers can consider not only lower spatial scale factors but can incorporate higher level spatial factors so that they can target management activities at high-priority spatial scales and areas.

Local catchments, HUCs, states, and FHPs also generally occur as a hierarchical series. An FHP consists of multiple states, a state consists of multiple HUCs, and an HUC consists of multiple local catchments. Such a partially nested structure not only reflects that factors at lower hierarchical spatial levels are influenced by factors at higher levels but implies that management of any particular aquatic feature and fish species for any river reach will be influenced by the state's management policies and implementation, which in turn will be influenced by collaborating efforts within an FHP. Additionally, many state and national river bioassessment programs use ecoregions and HUCs for sampling stratification and reporting. Incorporating such spatial units into our database provides the flexibility and efficiency of linking with the existing state and national river assessment programs.

The spatial hierarchical structure of our database can be visualized as a data table or a spreadsheet with many rows and columns. Each row in the table represents a river reach, and each column represents a variable that describes the river reach. This table includes all river reaches and contains all available attributes that describe the river reach channel conditions, network position and connectivity, local and network catchment natural and human disturbance conditions, and spatial hierarchical ecological and political boundaries. This table also provides users with the flexibility of adding new data (add more columns) that are available only to the region where the users are interested.

Such a spatial hierarchical database structure has several important implications. First, the river reaches in our database are mapped and riverine habitat condition assessment can be done for all rivers for the given mapping resolution. This con- trasts with the commonly used river condition assessment approaches, such as the EPA's Wadeable Stream Assessment (EPA 2006), which only applies to a small percentage of the rivers in a specific region but cannot provide condition assessment on all river reaches. Second, our database links every river reach with all available potential human disturbances at local and network catchments, which not only allows river assessment to be done for all reaches but permits assessments based on disturbance sources within landscapes rather than stressors within the rivers. The landscape-based assessment is especially helpful to managers for pinpointing dominant sources of disturbances on which management activities can focus. Last, the hierarchical spatial structure of our database provides the capability to summarize data at different spatial scales (Figure 1).

\section{Riverine Resource Physical Character- istics at Different Spatial Scales}

Our database consists of boundaries for 46 FENAs, 272 EDUs (a region where EDUs were not yet delineated was counted as one EDU), 9 aggregated ecoregions, 85 Level-III EPA ecoregions, $13 \mathrm{FHPs}, 48$ states, 2,104 8-digit HUCs, and about 2.6 million river reaches. Because catchment size, precipitation, air temperature, elevation, gradient, and groundwater contribution are critical factors that determine river physicochemical and biological characteristics and are often used for river habitat classification (e.g., Brenden et al. 2008; Lyons et al. 2009), we summarized the river reach characteristics using these six factors to describe the overall natural variation in river landscape conditions across the conterminous United States.

\section{River Reach Natural Characteristics across the Conterminous United States}

To describe the characteristics of the six natural descriptors, we classified each factor into four to six groups. These groupings were intended to describe the spatial distribution patterns of these factors and to provide a coarse-level understanding of the diversity of the resource at a national scale rather than to generate a meaningful ecological classification.

Based on literature review, we grouped the river reaches into six size classes based on network catchment area. We classified streams with catchments less than $10 \mathrm{~km}^{2}$ as headwaters, 10 to $100 \mathrm{~km}^{2}$ as creeks, $100-1,000 \mathrm{~km}^{2}$ as small rivers, $1,000-10,000 \mathrm{~km}^{2}$ as medium rivers, $10,000-25,000 \mathrm{~km}^{2}$ as large rivers, and greater than $25,000 \mathrm{~km}^{2}$ as greater rivers. River reaches having no network connection were classified as disconnected. Of the 5.6 million kilometers of streams and rivers (including artificial water lines flowing through ponds, lakes, reservoirs, wetland, and intermittent streams), the majority of reaches are headwaters $(58.9 \%)$ and creeks $(27.0 \%)$; small and medium rivers consist of $9.1 \%$ and $3.5 \%$ and large and greater rivers consist of $0.6 \%$ and $0.9 \%$ total stream and river length. When only free-flowing waters are included, the conterminous United States has about 4.9 million kilometers of streams and 
rivers, of which about $55.4 \%$ are headwaters, $29.9 \%$ are creeks, $9.8 \%$ are small rivers, $3.5 \%$ are medium rivers, $0.6 \%$ are large rivers, and $0.8 \%$ are greater rivers (Figure 2 ).

The five mean annual precipitation river reach classes were identified using a multivariate classification and regression tree analysis based on fish abundance data (De'ath and Fabricius 2000). The fish data were collected by the EPA's En- vironmental Monitoring and Assessment Program, the USGS's National Water-Quality Assessment Program, and the states' monitoring and assessment programs and included 4,450 river reaches across the 48 states. The river reaches in our database were repeatedly split into paired classes based on fish variables that minimize the sum of squared error between the observation and the mean in each class. We chose the least squares method to simply split river reaches into a maximum of five
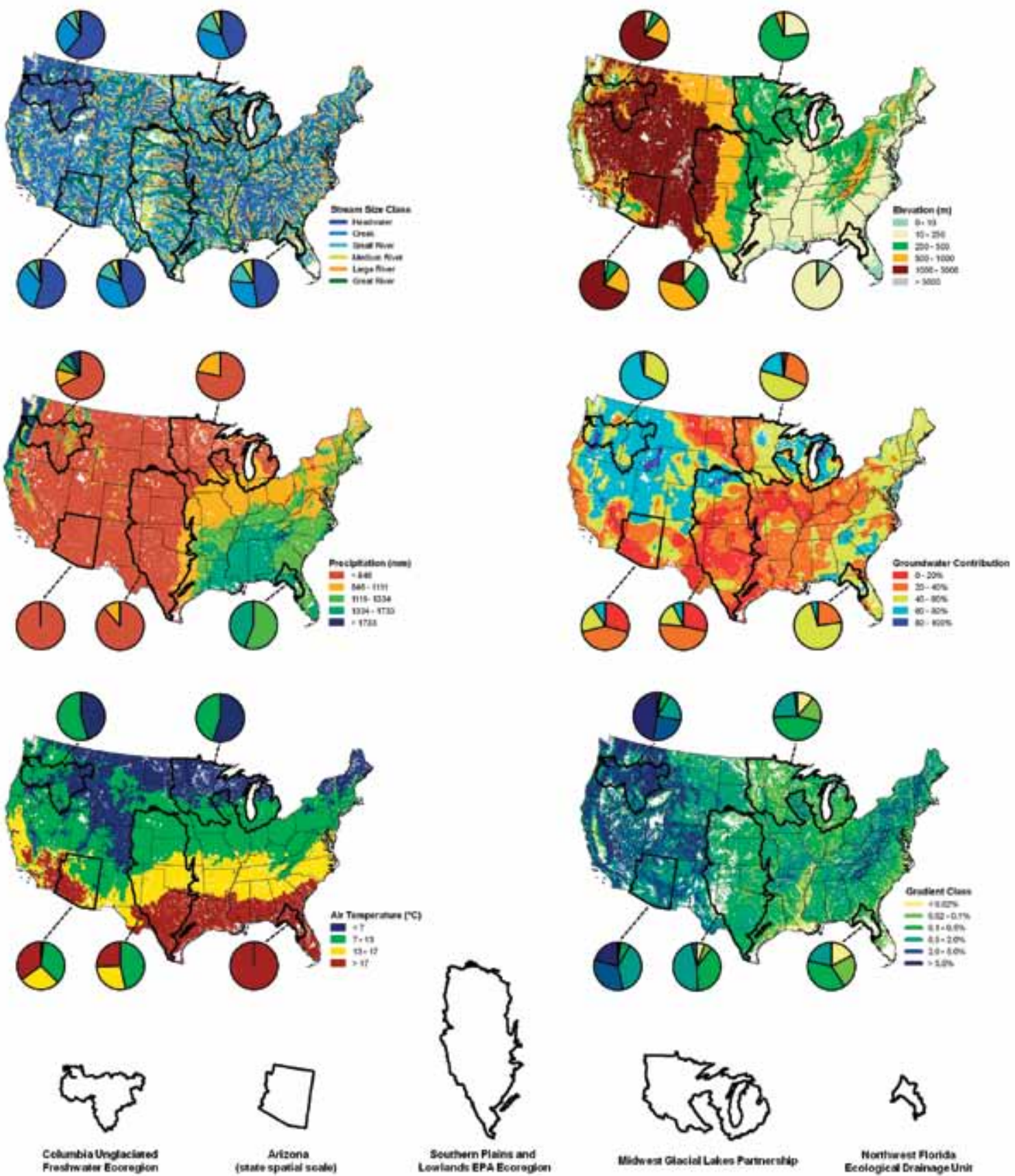

Figure 2. The six natural factors used for characterizing river reach natural variation across the conterminous United States. For river size class maps, impoundments are not shown. The pie charts are examples of data that were summarized at different spatial scales. 
classes to describe the spatial distribution patterns rather than to generate a meaningful ecological classification. We then applied the precipitation values that defined the classes to river reaches that do not have fish data. About $56 \%$ of river length receives less than $846 \mathrm{~mm}$ annual precipitation, $19 \%$ between 846 and $1,111 \mathrm{~mm}, 14 \%$ between 1,111 and $1,334 \mathrm{~mm}, 10 \%$ between 1,334 and $1,733 \mathrm{~mm}$ annual precipitation, and $1 \%$ receives greater than $1,733 \mathrm{~mm}$. The class of rivers with the highest precipitation in their catchments occurs primarily in the western coastal areas. The precipitation pattern in the eastern third of the lower 48 states is increasing from north to south, and precipitation for two-thirds of the middle states largely belongs to the lowest precipitation class (Figure 2).

The four mean annual air temperature river reach classes were identified based on multivariate classification and regression tree analysis using the same fish abundance data described above. About $27 \%$ of all river length flows through regions with mean annual air temperatures less than $7^{\circ} \mathrm{C}, 41 \%$ between $7^{\circ} \mathrm{C}$ and $13^{\circ} \mathrm{C}, 21 \%$ between $13^{\circ} \mathrm{C}$ and $17^{\circ} \mathrm{C}$, and $11 \%$ flows through regions with temperatures greater than $17^{\circ} \mathrm{C}$. As expected, mean annual air temperature shows a southward increasing pattern except for the Rocky Mountain region, which has high elevation (Figure 2).

Six elevation river reach classes were identified starting with a low-elevation class of less than $10 \mathrm{~m}$ above sea level suggested in the literature (McGranahan et al. 2007) and then subjectively dividing the rest of the elevation range into five groups. In the conterminous United States, about 3\% of river reach length is within an elevation of less than $10 \mathrm{~m}, 30 \%$ between 10 and $250 \mathrm{~m}, 22 \%$ between 250 and $500 \mathrm{~m}, 17 \%$ between 500 and $1,000 \mathrm{~m}, 29 \%$ between 1,000 and 3,000 m, and less than $1 \%$ at elevations greater than $3,000 \mathrm{~m}$. The higher elevation groups are mainly found in the western third of the country and the low-elevation groups are mainly distributed in the Midwest and Southeastern regions (Figure 2).

Six river reach gradient classes were identified based on criteria proposed by the Northeast Habitat Classification and Mapping Projects by The Nature Conservancy (http://www. glrc.us/documents/habitatworkshops/pdf/NYWorkshop/Tomajer090324.pdf). About 12\% of total river length has a gradient less than $0.03 \%, 6 \%$ between $0.02 \%$ and $0.1 \%, 21 \%$ between $0.1 \%$ and $0.5 \%, 33 \%$ between $0.5 \%$ and $2.0 \%, 15 \%$ between $2.0 \%$ and $5.0 \%$, and $13 \%$ has gradient greater than $5.0 \%$. The high-gradient streams are mainly distributed in the western areas and the low-gradient streams are mainly located in the midwestern areas of the conterminous United States (Figure 2).

We grouped the river reaches into five groundwater contribution classes using equal range values. About $18 \%$ of total river length has groundwater contribution less than 20\%, 33\% between $20 \%$ and $40 \%, 29 \%$ between $40 \%$ and $60 \%$, $19 \%$ between $60 \%$ and $80 \%$, and less than $1 \%$ has groundwater con- tribution greater than $80 \%$. The highest groundwater contribution areas are sparsely distributed in Michigan, Idaho, Oregon, and Nebraska. The high-groundwater contribution areas are located in the northwestern areas and low-groundwater contribution areas are in the south-central areas of the conterminous United States (Figure 2).

The six natural factors described above interactively influence river thermal and hydrologic regimes, substrate and channel characteristics, and physicochemical properties and consequently determine the national patterns of fish habitat distribution. The majority of the reaches (over $85 \%$ in length) are headwaters and creeks (less than $100 \mathrm{~km}^{2}$ catchment area), implying that great attention needs to be given to those reaches in order to maintain the health of the entire river systems in the United States. The lower air temperature resulting from high elevation in the Rocky Mountains and high altitude in northern regions and the spotted higher groundwater contribution areas are where the major relatively stable thermal and hydrologic habitats are found for various size streams and rivers. In contrast, it is generally expected that headwaters and creeks have habitat with varied temperature and flow regimes, small and medium rivers have moderately stable temperature and flow regimes, and large rivers have more stable temperature and flow regimes.

\section{River Reach Natural Characteristics Described by Different Spatial Scales}

Our database allows us to summarize natural descriptors attributed to reaches at various spatial units from individual river reaches and their associated local catchments to the entire nation. At the largest spatial scale (conterminous United States), the median values of temperature, elevation, gradient, groundwater contribution, and precipitation are $11^{\circ} \mathrm{C}, 358 \mathrm{~m}$, $0.8 \%, 42 \%$, and $885 \mathrm{~mm}$, respectively. At the intermediate spatial scales such as the aggregated ecoregions, the median values of the five variables are $10^{\circ} \mathrm{C}, 307 \mathrm{~m}, 1.2 \%, 41 \%$, and $887 \mathrm{~mm}$. At the finer spatial scales such as the 8-digit HUCs, the median values of the five variables are $11^{\circ} \mathrm{C}, 376 \mathrm{~m}, 1.1 \%, 43 \%$, and $819 \mathrm{~mm}$, respectively.

These factors summarized at different spatial scales show a dependency of central tendency and variability depending on the units chosen (Table 2). In general, FENA has the highest median values for air temperature, elevation, and river reach gradient and Level-III ecoregions have the highest median values for groundwater contribution and precipitation. For the six river size classes, the values for mean annual air temperature increased as river size increased. The values of river reach elevation, gradient, and precipitation generally decreased as river size increased. In contrast, the values for groundwater contribution did not show a clear trend (Table 2). 
TABLE 2. Summary statistics of natural factors at different spatial scales, including the conterminous United States (CUS), aggregated ecoregion (AgEco), Freshwater Ecoregions of North America (FENA), state, Level-III ecoregion (Ecoreg), ecological dranage unit (EDU), 8-digit hydrologic unit (HUC-8), and the six river size classes. HWT = headwater, CRK = creek, SRV = small river, MRV = medium river, LRV = large river, and GRV = greater river. See text for the river size classification criteria.

\begin{tabular}{|c|c|c|c|c|c|c|c|c|c|c|c|c|c|c|}
\hline & & cus & AgEco & FENA & State & Ecoreg & EDU & HUC-8 & HWT & CRK & SRV & MRV & LRV & GRV \\
\hline \multirow[t]{3}{*}{ Air temperature $\left({ }^{\circ} \mathrm{C}\right)$} & $90 \%$ & 17 & 17 & 20 & 17 & 17 & 18 & 18 & 17 & 18 & 18 & 18 & 18 & 19 \\
\hline & Median & 11 & 10 & 13 & 11 & 11 & 10 & 11 & 11 & 11 & 11 & 11 & 10 & 12 \\
\hline & $10 \%$ & 5 & 6 & 6 & 5 & 5 & 5 & 5 & 5 & 5 & 5 & 6 & 6 & 7 \\
\hline \multirow[t]{3}{*}{ Elevation (m) } & $90 \%$ & 1,792 & 1,502 & 1,757 & 1,744 & 1,689 & 1,751 & 1,752 & 1,845 & 1,808 & 1,683 & 1,525 & 1,462 & 1,131 \\
\hline & Median & 358 & 307 & 393 & 337 & 262 & 307 & 376 & 360 & 381 & 331 & 287 & 283 & 243 \\
\hline & $10 \%$ & 64 & 60 & 71 & 75 & 49 & 65 & 52 & 73 & 64 & 50 & 27 & 9 & 5 \\
\hline \multirow[t]{3}{*}{ Gradient (\%) } & $90 \%$ & 6.4 & 7.3 & 7.3 & 7.4 & 4.5 & 5.5 & 6.2 & 9.7 & 3.4 & 1.2 & 0.5 & 0.3 & 0.2 \\
\hline & Median & 0.8 & 1.2 & 1.7 & 1.2 & 1.0 & 1.1 & 1.1 & 1.4 & 0.5 & 0.1 & 0.0 & 0.0 & 0.0 \\
\hline & $10 \%$ & 0.0 & 0.4 & 0.4 & 0.2 & 0.4 & 0.3 & 0.2 & 0.2 & 0.0 & 0.0 & 0.0 & 0.0 & 0.0 \\
\hline \multirow[t]{3}{*}{ Groundwater Contribution (\%) } & $90 \%$ & 68 & 62 & 65 & 66 & 60 & 68 & 68 & 68 & 69 & 68 & 69 & 72 & 67 \\
\hline & Median & 42 & 41 & 41 & 42 & 47 & 46 & 43 & 42 & 43 & 43 & 45 & 47 & 43 \\
\hline & $10 \%$ & 19 & 30 & 22 & 22 & 26 & 22 & 18 & 20 & 18 & 19 & 21 & 23 & 22 \\
\hline \multirow[t]{3}{*}{ Precipitation (mm) } & $90 \%$ & 1,396 & 1,328 & 1,433 & 1,357 & 13,57 & 1,414 & 1,384 & 1,412 & 1,381 & 1,369 & 1,343 & 1,310 & 1,271 \\
\hline & Median & 885 & 887 & 776 & 917 & 1042 & 920 & 819 & 929 & 839 & 835 & 805 & 626 & 632 \\
\hline & $10 \%$ & 316 & 338 & 776 & 361 & 415 & 366 & 346 & 336 & 302 & 295 & 271 & 251 & 254 \\
\hline
\end{tabular}

\section{Landscape Disturbances to Riverine Resources at Different Spatial Scales}

The physicochemical and biological conditions along with their controlling processes of rivers in the conterminous United States have been substantially modified by landscape human activities, such as agricultural, urban, recreational, commercial, industrial, and transportation land uses; river network fragmentations; and point source pollutions (e.g., Paul and Meyer 2001; Wang et al. 2006, 2008). We summarized the percentages of agricultural, urban, and impervious land uses and densities of population, road crossing, road length, dams, and toxic release inventory sites to characterize human landscape disturbances at different spatial scales and river size classes. Although our database contains many more landscape human disturbance measures, the following summary of selected variables provides an overview of the patterns of riverine landscape disturbance across the conterminous United States.

\section{Landscape Disturbance to River Reaches across the Conterminous United States}

Statistics on river length that are impacted both heavily and minimally by each of the major landscape human disturbances provide a national perspective on the conditions of fluvial systems for the conterminous 48 states. Based on literature-reported thresholds of landscape human disturbance levels (e.g., Paul and Meyer 2001; Wang et al. 2003, 2008), about $1.1 \%$ of river length is strongly impacted by network catchment agricultural land use (>75\%) and $2.3 \%$ by urban land use $(>10 \%)$ across the conterminous United States. In contrast, about $14.5 \%$ of river length is minimally affected by catchment agricultural land use $(<10 \%)$ and $11.8 \%$ by urban land use $(<1 \%)$. Similarly, about $0.5 \%$ of river length is strongly impacted by catchment impervious land ( $>5 \%), 1.7 \%$ by human population $\left(>50\right.$ people $\left./ \mathrm{km}^{2}\right), 2.1 \%$ by roads density $(>2 \mathrm{~km} /$ $\left.\mathrm{km}^{2}\right)$, and less than $1 \%$ by dam density $\left(4 \mathrm{dams} / 100 \mathrm{~km}^{2}\right)$ or point source pollution (5 permits $\left./ 100 \mathrm{~km}^{2}\right)$. In contrast, about $1.1 \%$ of river length is minimally impacted by impervious land $(<0.1 \%), 5.6 \%$ by population density $\left(<1\right.$ person $\left./ \mathrm{km}^{2}\right), 1.9 \%$ by roads $\left(<0.5 \mathrm{~km} / \mathrm{km}^{2}\right), 1.1 \%$ by dams $\left(0 \mathrm{dam} / 100 \mathrm{~km}^{2}\right)$, and $3.3 \%$ by point source pollution ( 0 permit $/ 100 \mathrm{~km}^{2}$; Figure 3$)$.

Although the percentage of rivers that are strongly impacted by each disturbance alone appears small, the sum of the river lengths that are impacted by the eight disturbances is substantial (14.7\%). Additionally, the percentages of rivers that are jointly impacted by the accumulative influences of the disturbances could be magnified, although the actual level of each individual disturbance may be low or moderate.

In general, urban land use, impervious land, and population density are intercorrelated, and the majority of the impacted rivers are distributed in the eastern third of the United States and the western coastal states (Figure 3). Catchment agricultural land impacted a large number of rivers in the Midwestern states. Although road density and road crossings impacted the entire United States, they impacted more rivers in the eastern half of the country. Dam densities are particularly high for the Mississippi River drainage, and densities of both dams and point source pollution are high in the eastern portion of the United States. 

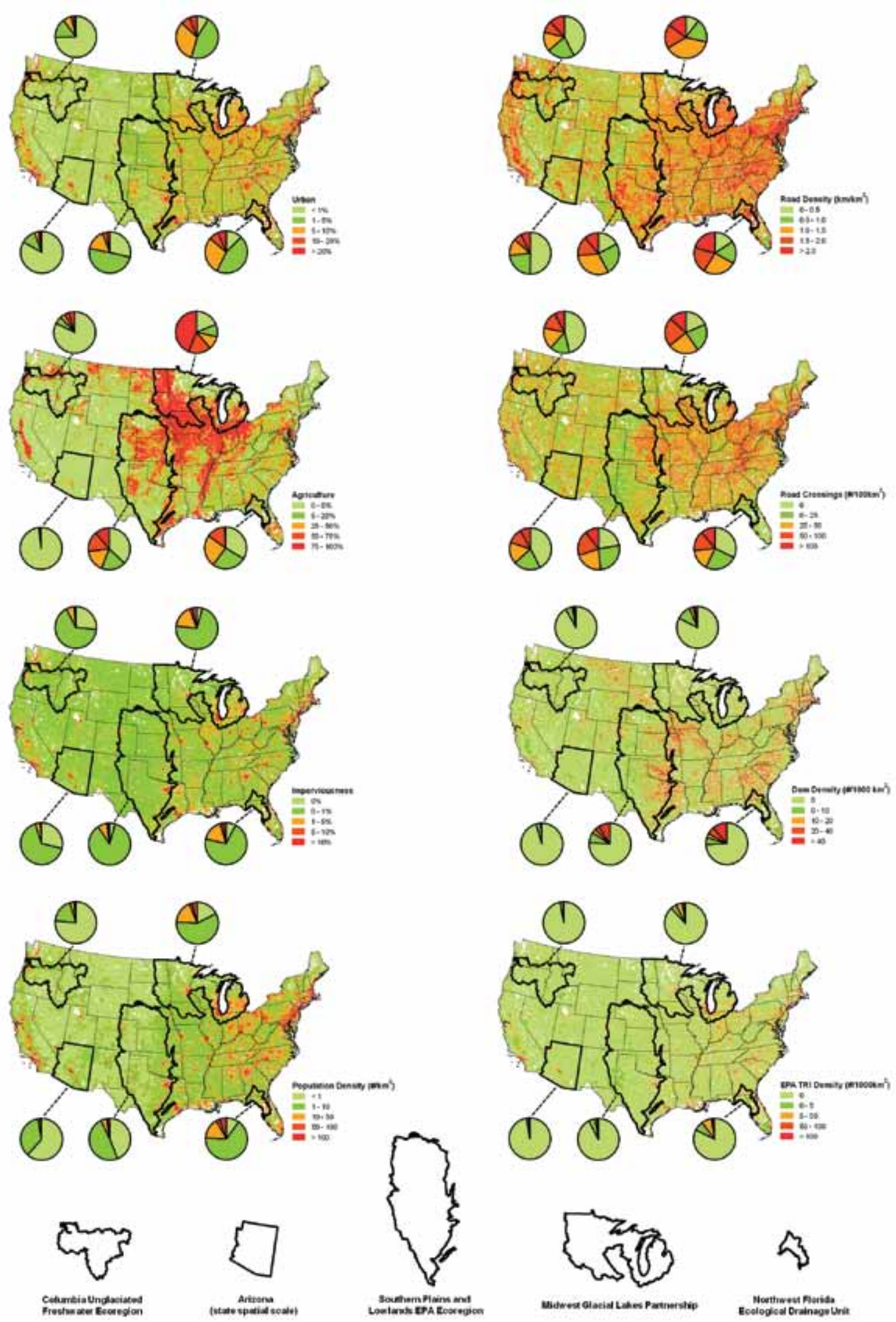

Figure 3. The eight human disturbance variables used for characterizing river reach conditions across the conterminous United States. The pie charts are examples of data that were summarized at different spatial scales. 


\section{Landscape Disturbance to River Reaches at Different Spatial Scales or Stream Classes}

Our database allows us to summarize landscape human disturbances attributed to reaches at any of the spatial units. At the largest spatial scale (conterminous United States), the median values of agriculture, urban, imperviousness, population, road crossings, road length, dams, and point source permits in the catchments of river reaches are $7.5 \%, 2.9 \%, 0.3 \%$, 2.4 people $/ \mathrm{km}^{2}, 32.0$ crossings $/ 100 \mathrm{~km}^{2}, 11.2 \mathrm{~km} / 100 \mathrm{~km}^{2}, 0.0$ dams $/ 1,000 \mathrm{~km}^{2}$, and 0.0 permits $/ 1,000 \mathrm{~km}^{2}$, respectively (Table 3). At the intermediate spatial scales such as the aggregated ecoregions, the median values of the eight variables are $23.0 \%$, $6.1 \%, 1.2 \%, 17.1$ people $/ \mathrm{km}^{2}, 63.8$ crossings $/ 100 \mathrm{~km} 2,13.2$ $\mathrm{km} / 100 \mathrm{~km}^{2}, 19.7$ dams $/ 1,000 \mathrm{~km}^{2}$, and 5.1 permits $/ 1,000 \mathrm{~km}^{2}$. At the finer spatial scales such as the 8-digit HUCs, the median values of the eight variables are $13.6 \%, 4.0 \%, 0.5 \%, 5.4 \%, 45.4$ crossings $/ 100 \mathrm{~km}^{2}, 12.5 \mathrm{~km} / 100 \mathrm{~km}^{2}, 5.2$ dams $/ 1,000 \mathrm{~km}^{2}$, and 0.8 permits $/ 1,000 \mathrm{~km}^{2}$, respectively.

The levels of catchment disturbances summarized at different spatial scales vary according to the spatial units chosen (Table 3). In general, the aggregated ecoregion scale has the highest median values for agriculture, urban, imperviousness, road crossings, dams, and point source permits and the state scale has the highest median values for agriculture and road length density. For the six river size classes, the median values for agriculture, imperviousness, population density, and dam density increased and that of road crossing density decreased as river size increased. There were no clear relationships between river size and the median values of urban land, road length density, and point source permits (Table 3 ).

The conterminous United States consists of varied levels in these catchment disturbances, and the variability of the levels is spatial unit-size dependent (Table 3). The 10th and 90th percentile values of agriculture, urban, imperviousness, population, road crossings, road length, dams, and point source permits in the catchments of river reaches across the 48 states are $0.0 \%$ and $77.8 \%, 0.0 \%$ and $9.4 \%, 0.0 \%$ and $1.6 \%, 0.0$ and 24.7 people $/ \mathrm{km}^{2}, 0.0$ and 105.0 crossings $/ 100 \mathrm{~km}^{2}, 0.4$ and 22.9 $\mathrm{km} / 100 \mathrm{~km}^{2}, 0.0$ and $17.8 \mathrm{dams} / 1,000 \mathrm{~km}^{2}$, and 0.0 and 0.0 permits $/ 1,000 \mathrm{~km}^{2}$, respectively. In general, data summarized at the state scale have the highest 10th and 90th percentiles for imperviousness, population, road length, dams, and point source permits and at the 48-state scale the highest 90th percentiles for agriculture and road crossing density. The 90th percentile values of agriculture land, road crossing density, road density, and dam density (except headwater) decreased, and that of population density increased as river size increased. The 90th percentile values of urban land, imperviousness, and point source permits did not show a clear relationship with river size (Table 3).

\section{Utility of the Spatial Framework and Database for NFHAP and Other Research and Management Programs}

Our hierarchical spatial framework and database assembles in one place all stream and river reaches and their associated descriptors for channel positions, network connectivity, and local and network catchment natural variation and human disturbances for the first time for the conterminous United States. This hierarchical spatial framework and database has a broad array of uses for NFHAP to achieve its goals and can help meet many other research, assessment, and management needs at national, regional, and local scales.

The framework and database provides NFHAP with the best available information about the amounts, types, and locations of natural and human landscape influences on the nation's river resources. This information is available for any specific stretch of a river; for entire river networks; and for rivers located within a specific local area, planning district, state, multistate region, FHP partnership region, or the entire conterminous United States. Such information can meet the needs of local stakeholders who are interested in only their local river reaches; watershed groups who are interested in specific catchments; local governments and planners who are managing counties or districts; state governments who are responsible for rivers within their state boundaries; partnerships who have common interests in regionally featured river resources; and the efforts of NFHAP in identifying and reporting national river resources within political or ecological boundaries by river types or by socially and economically important biological communities.

Our database not only provides information about rivers themselves but describes river reaches' network connectivity, position, and natural conditions of local and network catchments, which has very broad utilities for achieving NFHAP's goals and for other research, assessment, and management activities. This information is extremely important because the natural physicochemical and biological habitat characteristics of a river reach are largely determined by the geomorphic, land cover, and climate conditions at the channel, riparian, and local and network catchment scales, in addition to a river reach's network position and connectivity (e.g., Frissell et al. 1986; Poff 1997; Wang et al. 2006). An important potential use of our database is for ecological classification of ecosystem and macrohabitat types. River reach classification and physicochemical and biological expectation establishment are critical for natural resource policy-making, regulation, and scientific hypothesis testing. Previously, such classification and expectation were developed conceptually or based on selected river sites with sampled data (e.g., Frissell et al. 1986; Hawkins et al. 1993), which does not allow mapping of all river reaches into classes for a region. More recently, such a classification has been expanded to have the capability of mapping all river 
TABLE 3. Summary statistics of human disturbance factors at different spatial scales, including medians (Med), 90th percentiles (90\%), and 10th percentiles (10\%), for agricultural land use (Ag, \%), urban land use (Urb, \%), imperviousness (Imp, \%), human population density (Pop, \#/ km²), road crossing density (RdC, \#/100 km²), road density (RdL, $100 \mathrm{~m} / \mathrm{km}^{2}$ ), dam density (Dam, \#/1,000 $\mathrm{km}^{2}$ ), and toxic release inventory sites density (TRI, \#/1,000 km²) for conterminous United States (CUS), aggregated ecoregion (AgEcor), Freshwater Ecoregions of North America (FENA), state, Level-III ecoregion (Ecoreg), ecological drainage unit (EDU), 8-digit hydrologic unit (HUC-8), and the six river size classes. HWT = headwater, $\mathrm{CRK}=$ creek, SRV = small river, $\mathrm{MRV}=$ medium river, LRV $=$ large river, and GRV $=$ greater river. See text for the river size classification criteria

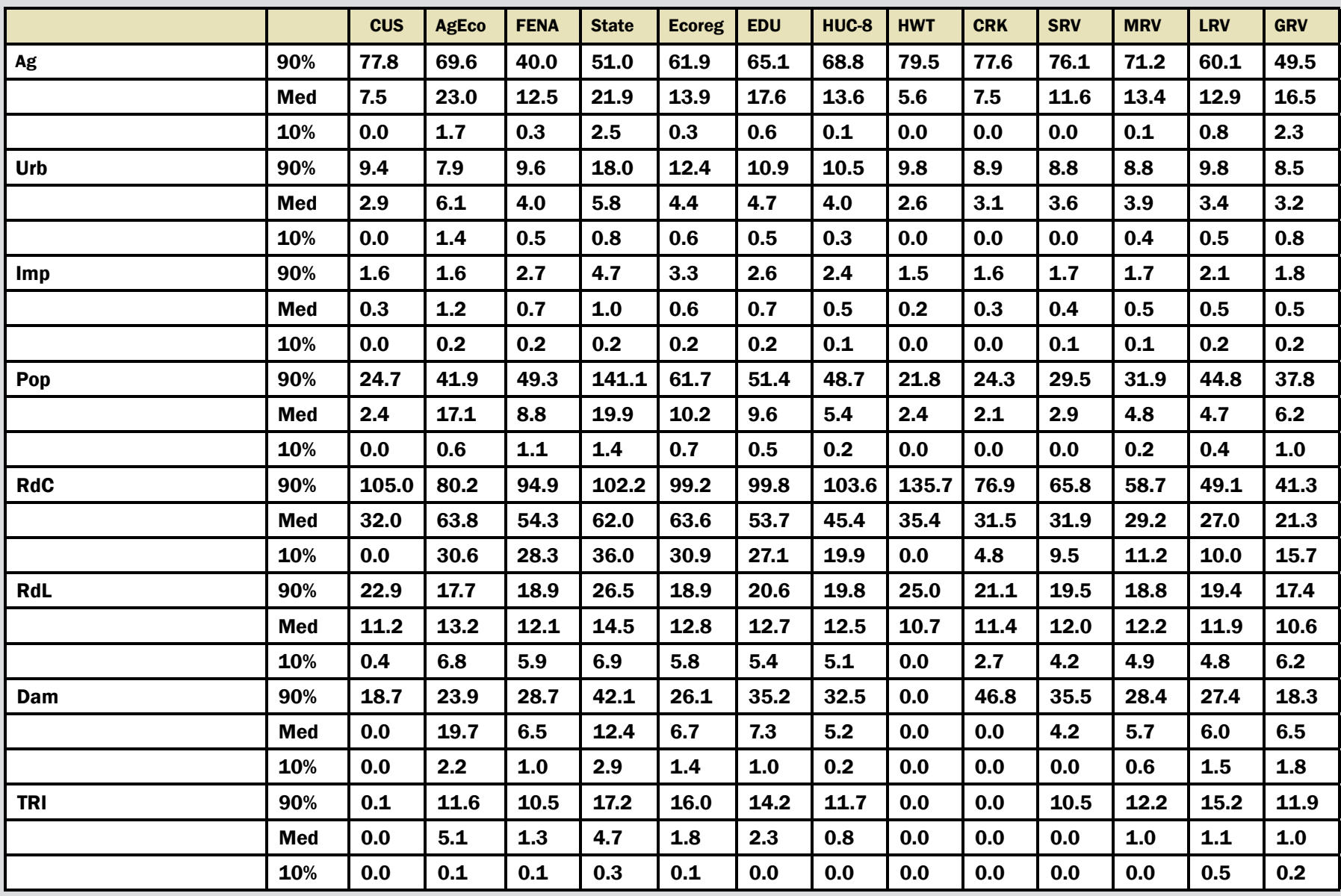

reaches for multistate regions (e.g., Brenden et al. 2008; Lyons et al. 2009). Using such an approach, our database makes it feasible to classify and map all river reaches across the conterminous United States.

Our database contains various human disturbance measures for each river reach at different spatial scales, which includes not only urban and agricultural land uses but many other measures, such as road and dam densities, point source pollutants, and nutrient loading (Table 1). This database integrates the majority of the best data sets currently available and consistently defined at a national scale. These human disturbance measures from multiple spatial scales are extremely valuable for conducting river health assessment for the entire conterminous United States (e.g., Esselman et al. 2011). This is because quantification of the influence of individual disturbance factors on river health for specific bodies of water is difficult as a result of the complexities in disturbance sources, types, and pathways.
The common approach for measuring human disturbance on streams is through multimetric biological, physical, or chemical indicators. Using such an approach, river health can only be assessed for areas for which those data are available, which may comprise only a fraction of total river reaches within a region. Also, many of the currently used indicators lack connection with specific human disturbances, making it difficult to pinpoint sources of ecosystem change and to prescribe preventive or restorative management actions (e.g., Norris and Hawkins 2000; Suter et al. 2002). In contrast, our database provides the essential data for quantifying human disturbance levels that could be applied to all river reaches without requiring field sampling within a given region, for pinpointing specific source of degradation, and for identifying reference conditions, which is a critical step in assessing human disturbances of stream health (Danz et al. 2007; Wang et al. 2008, 2010).

Our database is not without weakness. Data spatial reso- 
lution and availability of nationwide data are the two major obstacles for our database development. For example, although the database enables us to map all river reaches and calculate their positions and connectivity based on 1:100,000 NHDPlus, their accuracy could be improved substantially when the 1:24,000 NHDPlus becomes available nationally. Some of the data attributed to each river reach, such as reach position, connectivity, and land use/cover are suitable for uses at all scales, whereas others, such as nutrient yield and water use data, are suitable only for analyses and reporting at larger spatial scales. Our database does not include local-scale data, such as bank erosion, farm animal grazing, and trampling data that require field measurement and other local point and nonpoint source disturbance data that can be obtained from local agencies. Such data do exist for many regions of the nation and can be incorporated into the database by regional or local users. Additionally, the human disturbances in the database describe only a temporal snapshot of the health conditions of the river, which do not take into account legacy effects and future human activities (Wang et al. 2008).

Overall, our database provides the essential data for achieving the NFHAP objectives and for meeting the needs of many other research, assessment, and management programs. The utility of the database can be improved by incorporating additional detailed localized information that is not available at a national scale. Presently, many additional data layers and data layers with better resolution are available only at a regional scale. Adding those data to our national database by regional agencies or partnerships will provide them with the needed information that otherwise could not be supplied by the national database. This database can also be improved by incorporating more updated or new national data layers, projected land use changes, and predicted river physicochemical and biological conditions under projected climate changes. The downloadable beta version database is available at http://ec2-184-73-4015.compute-1.amazonaws.com/nfhap/main/.

\section{Acknowledgments}

We thank Paul Seelbach, Jonathan Higgins, and many other members of the National Fish Habitat Action Plan Data and Science Committee for their guidance in the development of the database. Tom Kwak, Tyler Wagner, and three anonymous reviewers provided insightful suggestions that substantially improved the manuscript. This project was partially founded by the National Fish Habitat Action Plan contracted through Michigan State University and in-kind support from Michigan Department of Natural Resources. Any use of trade names is for descriptive purposes only and does not imply endorsement by the U.S. Government.

\section{References}

Abell, R. A., D. M. Olson, E. Dinerstein, P. Hurley, J. T. Diggs, W. Eichbaum, S. Walters, W. Wettengel, T. Allnutt, C. J. Loucks, and P. Hedao. 2000. Freshwater ecoregions of North America: a conservation assessment. Island Press, Washington, D.C.

Allan, D. 2004. Landscape and riverscapes: the influence of land use on river ecosystems. Annual Reviews of Ecology, Evolution and Systematics 35:257-284.

Brenden, T. O., R. D. Clark, A. R. Cooper, P. W. Seelbach, L. Wang, S. S. Aichele, E. G. Bissell, and J. S. Stewart. 2006. A GIS framework for collecting, managing, and analyzing multi-scale landscape variables across large regions for river conservation and management. Pages 49-74 in R.M. Hughes, L. Wang, and P.W. Seelbach, editors. Influences of landscapes on stream habitats and biological assemblages. American Fisheries Society, Symposium 48, Bethesda, Maryland.

Brenden, T., L. Wang, and P. W. Seelbach. 2008. A landscape-based river classification system for Michigan rivers and streams for fisheries and environmental management. Transactions of the American Fisheries Society 137:1621-1636.

Danz, N. P., G. J. Niemi, R. R. Regal, T. Hollenhorst, L. B. Johnson, J. M. Hanowski, R. P. Axler, J. J. Ciborowwski, T. Hrabik, V. J. Brady, J. R. Kelly, J. A. Morrice, J. C. Brazner, R. W. Howe, C. A. Johnston, and G. E. Host. 2007. Integrated measures of anthropogenic stress in the U.S. great Lakes basin. Environmental Management 39:631-647.

De'ath, G., and K. E. Fabricius. 2000. Classification and regression trees: a powerful yet simple technique for ecological data analysis. Ecology 81:3178-3192.

EPA (Environmental Protection Agency). 2006. Draft wadeable streams assessment: a collaborative survey of the nation's streams. USEPA, Report 841-B-06-002, Washington, D.C.

Esselman, P. C., D. M. Infante, L. Wang, D. Wu, A. Cooper, and W. W. Taylor. 2011. A preliminary assessment of cumulative catchment disturbance levels for river fish habitats of the conterminous United States. Restoration Ecology 29:133-151.

Frissell, C. A., W. J. Liss, C. E. Warren, and M. D. Hurley. 1986. A hierarchical framework for stream habitat classification: viewing streams in a watershed context. Environmental Management 10:199-214.

GAO (General Accounting Office). 2000. Water quality: key EPA and state decisions limited by inconsistent and incomplete data. The United States General Accounting Office, Report GAO/ RCED-00-54, Washington, D.C.

Gergel, S. E., M. G. Turner, J. R. Miller, J. M. Melack, and E. H. Stanley. 2002. Landscape indicators of human impacts to riverine systems. Aquatic Sciences 64:118-128.

Hawkins, C.P., J. L. Kerschner, P. A. Bisson, M. D. Bryant, L. M. Decker, S. V. Gregory, D. A. McCoullough, C. K. Overton, G. Reeves, R. J. Steedman, and M. K. Young. 1993. A hierarchical approach to classifying stream habitat features. Fisheries 18(6):3-11.

Higgins, J. V., M. T. Bryer, M. L. Khoury, and T. W. Fitzhugh. 2005. A freshwater classification approach for biodiversity conservation planning. Conservation Biology 19:432-445.

Karr, J. R., and E. W. Chu. 1997. Biological monitoring and assessment: using multimetric indexes effectively. USEPA, Report EPA 235-R97-001, Washington, D.C.

Lyons, J., T. Zorn, J. Stewart, P. Seelbach, K. Wehrly, and L. Wang. 2009. Defining and characterizing coolwater streams and their fish assemblages in Michigan and Wisconsin, USA. Transactions of the American Fisheries Society 29:1130-1151.

Mattson, K. M., and P. L. Angermeier. 2007. Integrating human impacts and ecological integrity into a risk-based protocol for con- 
servation planning. Environmental Management 39:125-138.

Maxwell, J. R., C. J. Edwards, M. E. Jensen, S. J. Paustain, H. Parrott, and D. M. Hill. 1995. A hierarchical framework of aquatic ecological units in North America (Nearctic Zone). North Central Forest Experiment Station, USDA Forest Service, St. Paul, Minnesota.

McGranahan, G., D. Balk, and B. Anderson. 2007. The rising tide: assessing the risks of climate change and human settlements in low elevation coastal zones. Environment \& Urbanization 19:17-37.

Norris, R. H., and C. P. Hawkins. 2000. Monitoring river health. Hydrobiologia 435:5-17.

Omernik, J. M. 1987. Ecoregions of the conterminous United States. Map (scale 1:7,500,000). Annals of the Association of American Geographers 77:118-125.

Paul, M. J., and L. Meyer. 2001. Streams in the urban landscape. Annual Review of Ecology and Systematics 32:333-365.

Poff, N. L. 1997. Landscape filters and species traits: towards mechanistic understanding and prediction in stream ecology. Journal of the North American Benthological Society 16:391-409.

Pont, D., R. M. Hughes, T. R. Whittier, and S. Schmutz. 2009. A predictive index of biotic integrity model for aquatic-vertebrate assemblages of Western U.S. streams. Transactions of the American Fisheries Society 2009 138:292-305.

Seaber, P. R., Kapinos, F. P., and Knapp, G. L. 1987. Hydrologic units maps. U.S. Geological Survey Water-Supply Paper 2294.

Sowa, P. S., G. Annis, M. E. Morey, and D. D. Diamond. 2007. A gap analysis and comprehensive conservation strategy for riverine ecosystems of Missouri. Ecological Monographs 77:301-334.

Stoddard, J. L., D. V. Peck, S. G. Paulsen, J. Van Sickle, C. P. Hawkins, A. T. Herlihy, R. M. Hughes, P. R. Kaufmann, D. P. Larsen, G. Lomnicky, A. R. Olsen, S. A. Peterson, P. L. Ringold, and T. R. Whittier. 2005. An ecological assessment of western streams and rivers. EPA 620/R-05/005, U.S. Environmental Protection Agency, Washington, DC.

Suter, G. W., II, S. B. Norton, and S. M. Cormier. 2002. A methodology for inferring the causes of observed impairments in aquatic ecosystems. Environmental Toxicology and Chemistry 21:11011111.

Wang, L., T. Brenden, P. W. Seelbach, A. Cooper, D. Allan, R. Clark, Jr., and M. Wiley. 2008. Landscape based identification of human disturbance gradients and references for streams in Michigan. Environmental Monitoring and Assessment 141:1-17.

Wang, L., J. Lyons, P. Rasmussen, P. Kanehl, P. Seelbach, T. Simon, M. Wiley, E. Baker, S. Niemela, and M. Stewart. 2003. Influences of landscape and reach scale habitat on stream fish communities in the northern lakes and forest ecoregion. Canadian Journal of Fisheries and Aquatic Science 60:491-505.

Wang, L., P. W. Seelbach, and R. Hughes. 2006. Introduction to landscape influences on stream habitats and biological assemblages. American Fisheries Society, Symposium 48:1-23.

Wang, L., K. Wehrly, J. Breck, and L. S. Kraft. 2010. Landscape based assessment of human disturbance for Michigan lakes. Environmental Management 46:471-483.

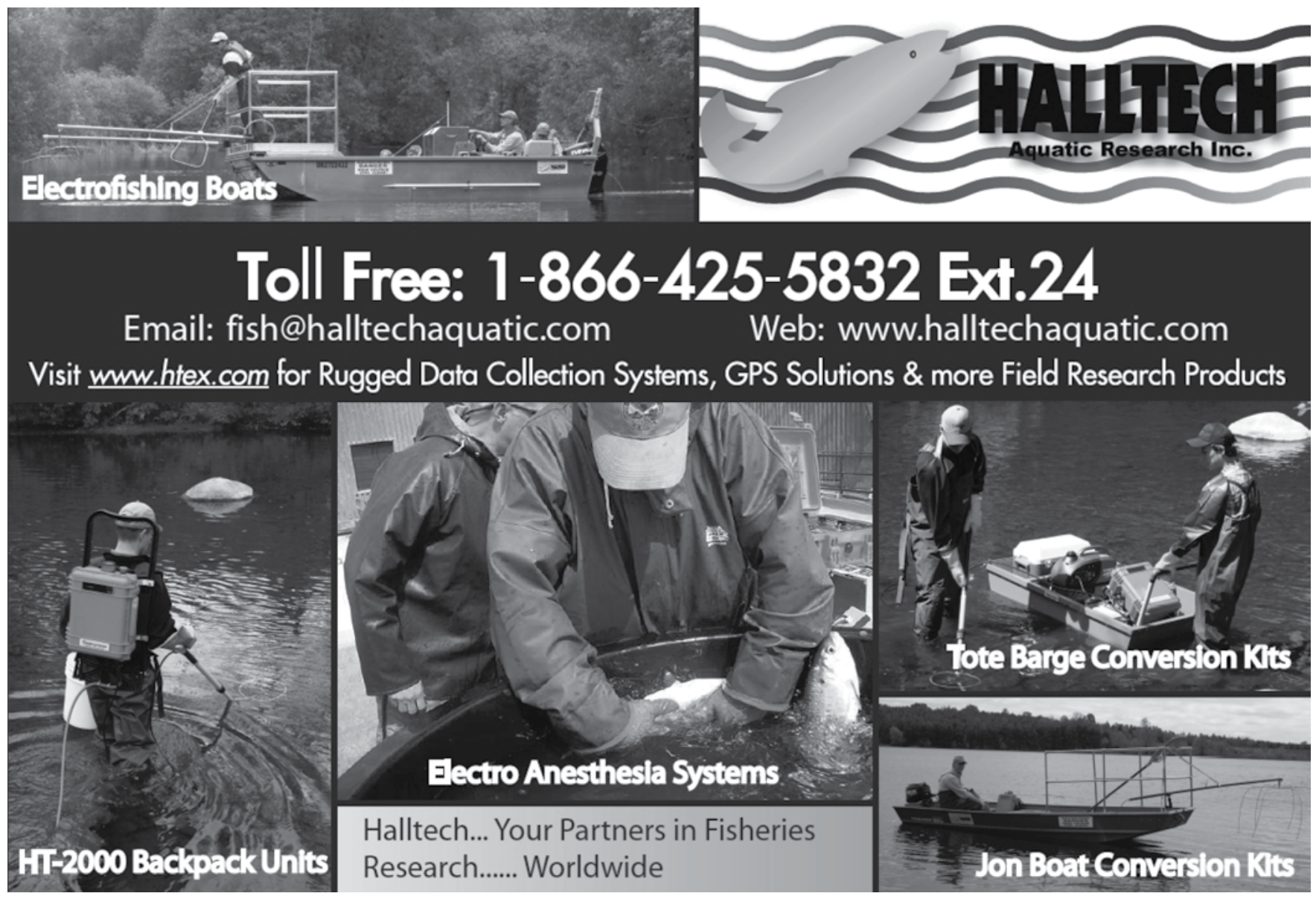

